\title{
STUDIES OF OESOPHAGEAL MOTILITY, WITH SPECIAL REFERENCE TO THE DIFFERENTIAL DIAGNOSIS OF DIFFUSE SPASM AND ACHALASIA (CARDIOSPASM)
}

BY

\author{
ARTHUR M. OLSEN AND BRIAN CREAMER* \\ From the Sections of Medicine and of Physiology, Mayo Clinic and Mayo Foundation, Rochester, \\ Minnesota
}

(RECEIVED FOR PUBLICATION OCTOBER 24, 1957)

It is not easy to study the oesophageal component of deglutition. The act of swallowing is complex, and food or fluid passes rapidly to the stomach. The speed at which a contrast medium traverses the oesophagus makes it difficult for the radiologist to analyse the mechanisms involved. Nevertheless, our knowledge of oesophageal physiology by radiology has been considerably increased, and the introduction of cineradiography should expand this field.

We have been especially interested in the study of oesophageal motility by measurements of pressures within the body of the oesophagus and at its superior and inferior sphincters, and also in the hypopharynx and the fundus of the stomach. Characteristic patterns of motility have been demonstrated for the oesophagus in health and in a variety of disease entities (Butin, Olsen, Moersch, and Code, 1953; Creamer, Olsen, and Code, 1957 : Dornhorst, Harrison, and Pierce, 1954 ; Fyke, Code, and Schlegel, 1956; Hightower, Olsen, and Moersch, 1954 ; Kramer and Ingelfinger, 1949). The method has proved to be of considerable value in the differential diagnosis of oesophageal disorders and disturbances of the cardia.

From a practical standpoint, studies of motility thus far have had their greatest value to the clinician in the differentiation of achalasia (or cardiospasm) from diffuse spasm of the oesophagus. Although these conditions are physiological opposites, they have frequently been confused in medical literature. For many years achalasia has been called "cardiospasm," although its actual basis is failure of the musculature of the oesophagus to react in peristaltic fashion after deglutition. The term "achalasia" (Greek: not-relaxation) describes the condition more accurately than does "cardiospasm," because the obstruction

*Now Lecturer in Medicine. St. Thomas' Hospital. London. is an absence of relaxation rather than a true spasm of the lower sphincter; yet achalasia as a term does not include the motor failure of the oesophageal musculature which is part of the condition. Another term used as a synonym, "mega-oesophagus," properly signifies only the enlargement of the oesophagus which is an end-result of the disorder. The clinical syndrome of diffuse spasm, or non-sphincteric oesophagospasm, is less well known and frequently has been diagnosed as early achalasia. Actualıy, diffuse spasm is a spastic contraction of the lower two-thirds of the oesophagus often associated with hypertrophy of the smooth muscle. The principal characteristics of these conditions will be discussed later. Inasmuch as the treatment and the prognosis for the two are different, separation of the entities is important. Studies of motility have been of inestimable value in the differentiation of these conditions. Even so, there is a small group of cases in which the interpretation of our pressure records is difficult.

In this report we will describe briefly our methods of meas Iring oesophageal pressures. The characteristic findings in normal individuals will be outlined, and the motility patterns in achalasia and in diffuse spasm will be compared and contrasted. We shall illustrate the role of motility studies in the differential diagnosis of these conditions.

\section{Methods}

Pioneer work in the measurements of oesophageal pressures was done by Kronecker and Meltzer (1883) with the aid of balloons. The balloon technique was used by Carlson and Luckhardt (1921) and by Cannon (1911) in physiological studies, and more recently by Kramer and Ingelfinger (1949). An inflated balloon itself stimulates an oesophageal response and therefore this method has limitations. Open-tip waterfilled tubes connected to sensitive manometers have 


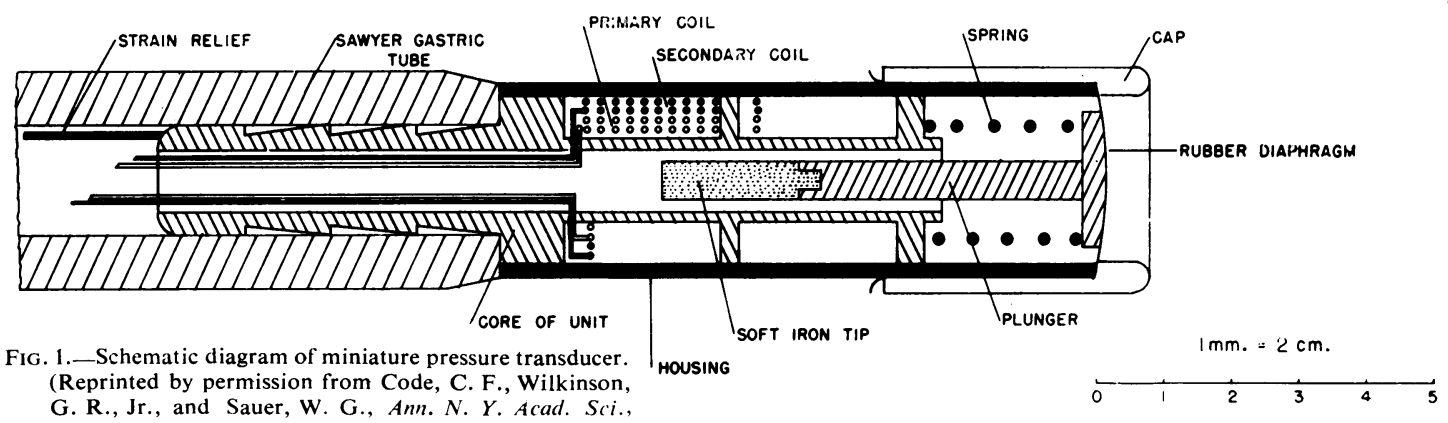

1954, 58, 317.)

been used by Dornhorst and associates (1954) for recording resting pressures and response to swallowing.

In our laboratory, the most satisfactory device for recording changes in intraluminal pressure has been a minute electromagnetic pressure transducer con-

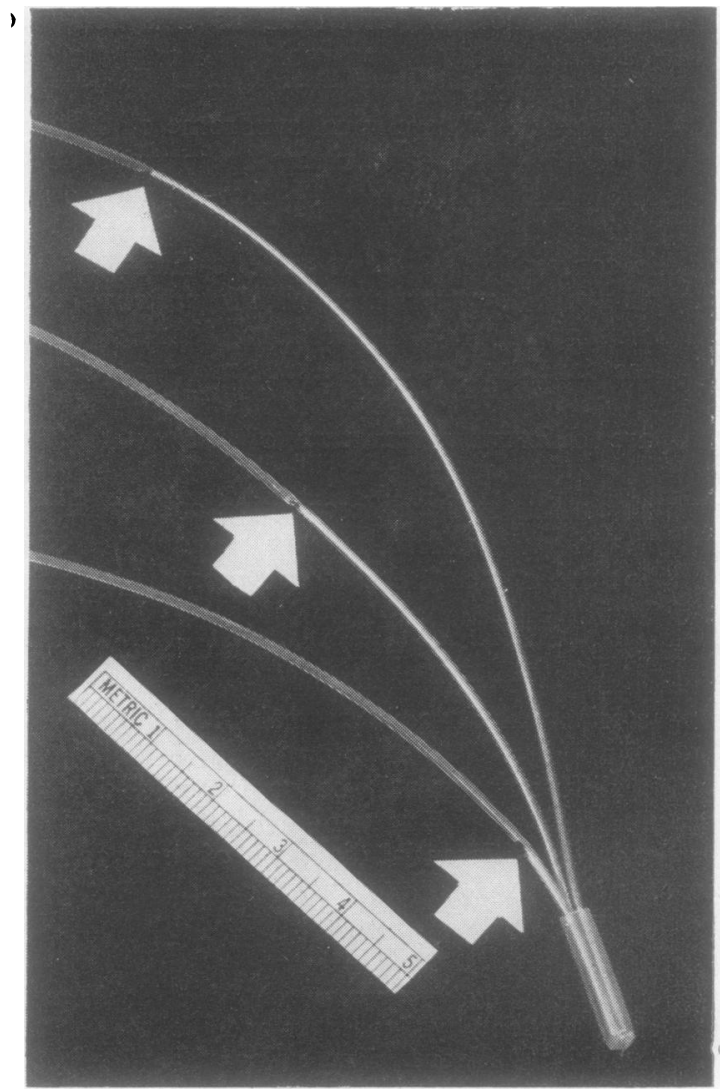

FIG. 2.-Polyethylene water-filled tubes for passage into oesophagus. Lateral openings at intervals of 3 to $10 \mathrm{~cm}$. permit simultaneous measurement of pressure at different levels in the oesophagus. Proximal ends of these tubes are connected to three pressure transducers like the one illustrated in Fig. 1. (Reprinted by permission from Creamer, Brian, Olsen, A. M., and Code, C. F. Gastroenterology, 1957, 33, 293.) structed atter the design of Gauer and Gienapp (1950) and Wetterer (1943) (Fig. 1). The transducer measures $3 \mathrm{~mm}$. in diameter and $13 \mathrm{~mm}$. in length. This unit may be attached in the end of a No. 14 Sawyer tube. or in the end of plastic tubing of similar size. and $\Phi$ passed to the desired recording site, where it detects the changes in pressure directly.

Simultaneous recordings from different levels in the oesophagus provide more revealing information of than pressures recorded from only one site at a time. . To form the apparatus, three polyethylene tubes similar to those used by Dornhorst and others (1954) are fastened together at the tips, and in each tube a hole is cut, the interval separating their different levels being usually $5 \mathrm{~cm}$. (Fig. 2). After the tubes have been swallowed, they are attached to pressure transducers and filled with water. The changes in pressures are then recorded indirectly, being conducted from the site of detection to the transducers by the columns of water in the tubes. The apparatus and technique for both the direct and the indirect methods have been described previously (Creamer and others, 1957 ; Fyke and others, 1956).

\section{Summary OF ObSERVATIONS}

Table I sets these out comparatively.

TABLE I

COMPARISON OF MOTILITY STUDIES IN HEALTH, ACHALASIA, AND DIFFUSE SPASM

\begin{tabular}{|c|c|c|c|}
\hline Sites & Health & Achalasia & Diffuse Spasm \\
\hline $\begin{array}{c}\text { At rest : } \\
\text { Upper } \\
\text { sphincter } \\
\text { Oesophagus } \\
\text { Lower } \\
\text { sphincter }\end{array}$ & $\begin{array}{l}\text { Band of high } \\
\text { pressure } \\
\text { Subatmospheric } \\
\text { Band of high } \\
\text { pressure }\end{array}$ & $\begin{array}{l}\text { Band of high } \\
\text { pressure } \\
\text { Atmospheric } \\
\text { Band of high } \\
\text { pressure }\end{array}$ & $\begin{array}{l}\text { Band of high } \\
\text { pressure } \\
\text { Subatmospheric } \\
\text { Wider band of } \\
\text { high pressure }\end{array}$ \\
\hline $\begin{array}{l}\text { In deglutition: } \\
\text { Upper } \\
\text { sphincter } \\
\text { Oesophagus }\end{array}$ & $\begin{array}{l}\text { Relaxes then } \\
\text { contracts } \\
\text { Peristaltic wave } \\
\text { of entire oeso- } \\
\text { phagus }\end{array}$ & $\begin{array}{l}\text { Relaxes then } \\
\text { contracts } \\
\text { Complete fail- } \\
\text { ure or feeble } \\
\text { simultan- } \\
\text { eous con- } \\
\text { tractions } \\
\text { No relaxation, } \\
\text { early con- } \\
\text { traction }\end{array}$ & $\begin{array}{l}\text { Relaxes, then } \\
\text { contracts } \\
\text { Upper third nor- } \\
\text { mal; lower } 23 \\
\text { simultaneous, } \\
\text { repetitive con- } \\
\text { tractions with } \\
\text { high pressures } \\
\text { Relaxes, then } \\
\text { contracts vig- } \\
\text { orously, some- } \\
\text { times too early }\end{array}$ \\
\hline
\end{tabular}




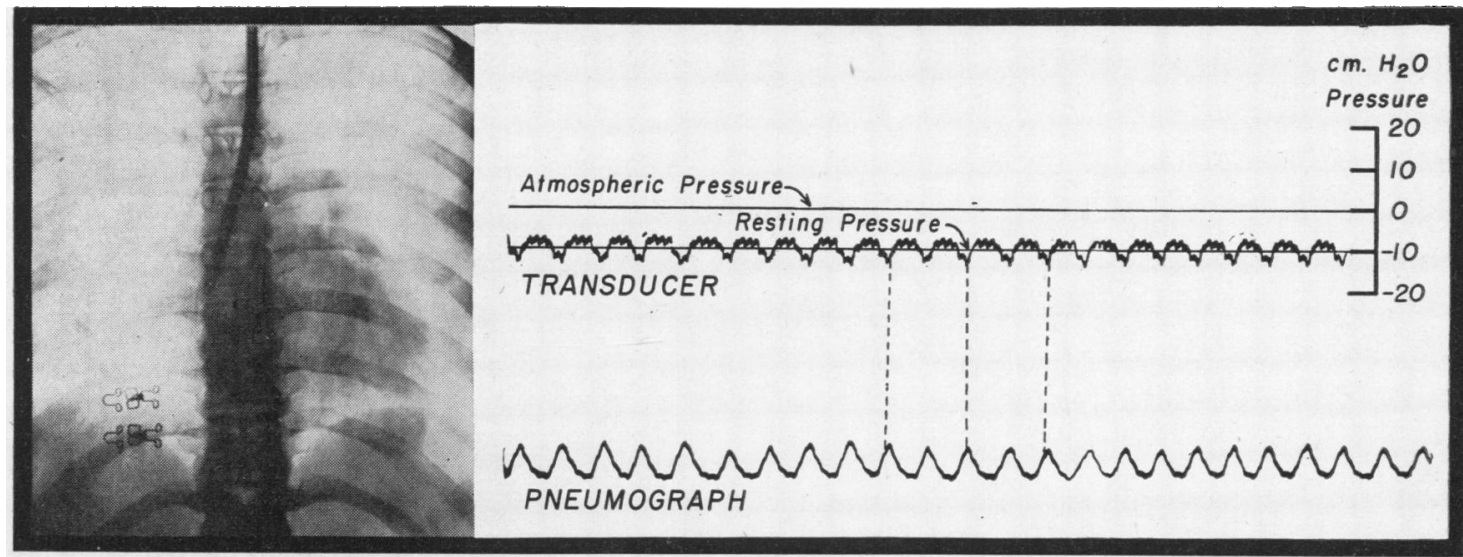

Fig. 3.-Position of pressure detector in mid-oesophagus, and normal resting pressure there. Note decrease of oesophageal pressure with inspiration (upward deflection of pneumograph) and increase in oesophageal pressure with expiration. (Record reprinted by permission from Hightower, N. C., Jr., Olsen, A. M., and Moersch, H. J., Gastroenterology, 1954, 26, 592.)

IN Health.- - As detailed accounts of motility of the oesophagus and its sphincters in health have been reported (Butin and others, 1953 ; Fyke and others, 1956), only the more significant findings can be mentioned here. Recordings of pressure have been made both in the resting state and after swallowing. Within the body of the oesophagus (Fig. 3), the resting pressure is subatmospheric.

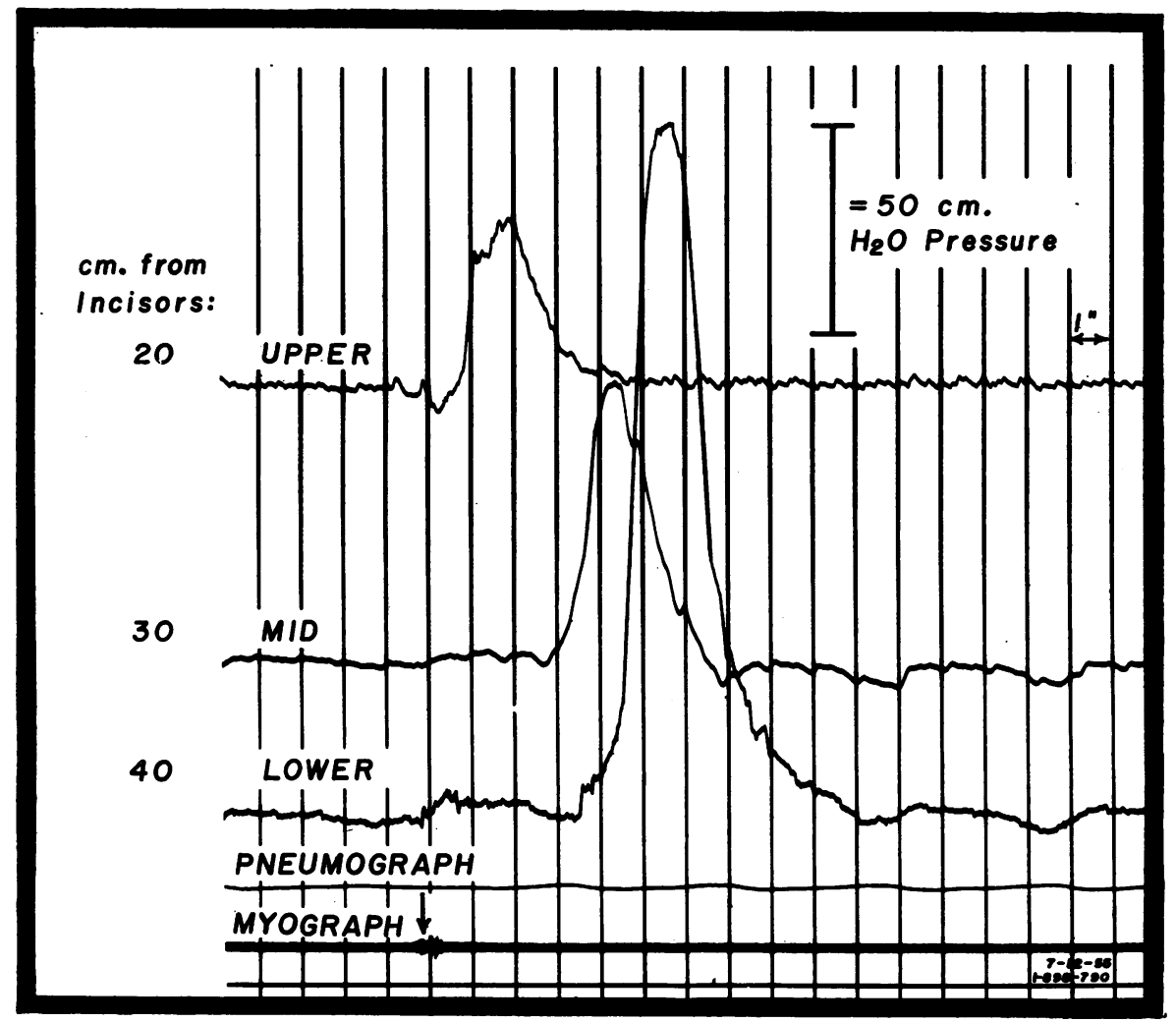

FIG. 4.-Normal deglutitory pressure sequence in upper, middle, and lower oesophagus. 
(about 5 to $15 \mathrm{~cm}$.), and reflects the intrathoracic pressure. Fluctuations occur with respiration, the pressure decreasing with inspiration and increasing with expiration. Resting pressures in the fundus of the stomach are equal to or slightly above atmospheric pressure, depending on the subject's position. In the stomach the pressure increases with inspiration and decreases with expiration. As a detecting unit is withdrawn slowly from the stomach into the oesophagus, the relationship of the pressure changes with breathing become reversed.

Measurements of deglutitory pressures within the normal oesophagus at various levels show that a well co-ordinated peristaltic wave passes all the way to the lower oesophageal sphincter. The intensity of the waves varies between 50 and $100 \mathrm{~cm}$. of water pressure and is stronger in the lower part of the oesophagus (Fig. 4). The peak of the pressure induced by the peristaltic contraction reaches the lower end of the oesophagus about 9 to 10 seconds (Fig. 5) after swallowing is initiated.
At the upper oesophageal sphincter (pharyngooesophageal junction) a band of elevated pressure about $2.5 \mathrm{~cm}$. in width is found under resting conditions (Fig. 6a). The mean maximal pressure in this region is about $40 \mathrm{~cm}$. of water more than oesophageal pressure and an equal amount more than pharyngeal pressure (Fyke and Code, 1955). At the beginning of deglutition a pressure of about 50 to $100 \mathrm{~cm}$. of water develops in the hypopharynx. Simultaneously the pressure decreases sharply in the upper oesophageal sphincter, indicating relaxation of the sphincter at the same time as the pharynx contracts. After its relaxation, the sphincter contracts as the wave of high pressure passes through it. This wave, which starts in the pharynx and passes through the pharyngooesophageal sphincter, is peristaltic; and within the oesophagus it is the "primary peristaltic" wave of that organ.

At the oesophago-gastric junction also the resting pressures are elevated, although the differences are not so great as at the pharyngo-oesophageal

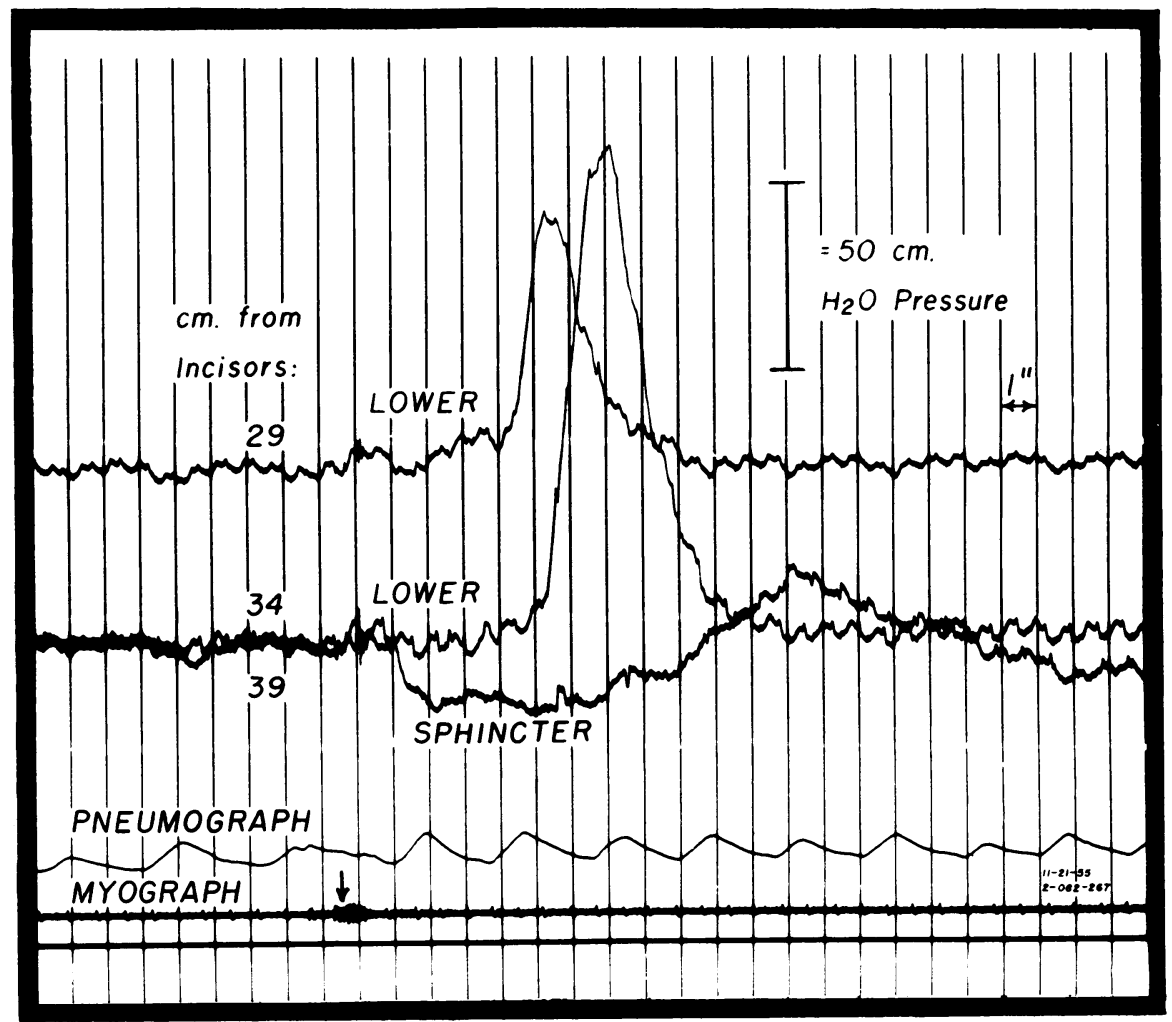

FIG. 5. - Normal deglutitory pressure sequence in lower oesophagus and at lower sphincter, showing wave of relaxation followed by late wave of high pressure as peristaltic wave passes sphincter. (Reprinted by permission from Fyke, F. E., Jr.. Code, C. F., and Schlegel, J. F., Gastroenterologia, 1956, 86, 135.) 


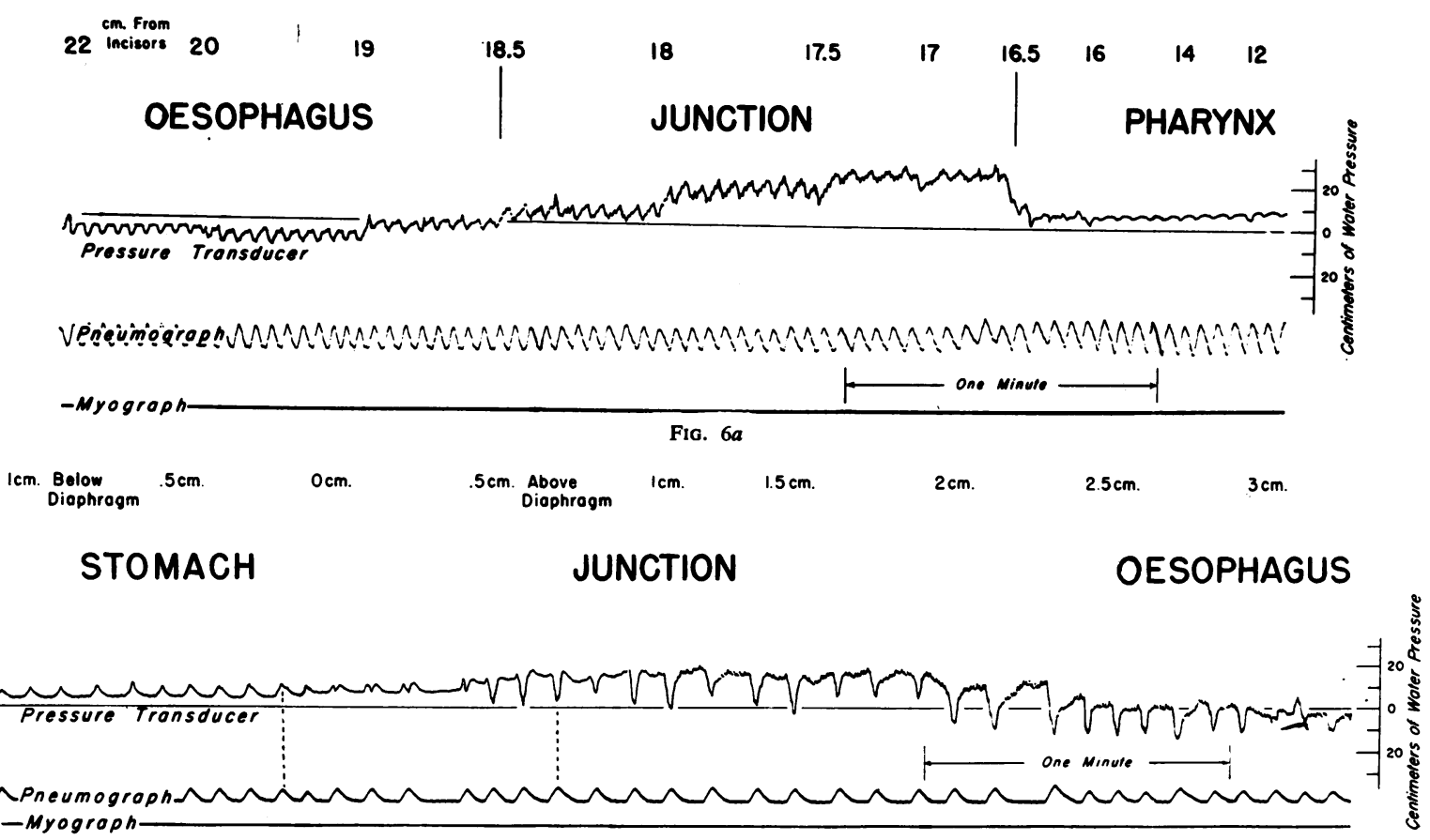

FIo. $6 b$

FIG. 6.-Normal resting pressures at the sphincters. $a$, Pharyngo-oesophageal junction. Withdrawal of transducer from oesophagus to pharynx. $b$, Oesophago-gastric junction. Withdrawal of transducer from stomach to oesophagus.

level (Fig. 6b). The sphincteric pressure (endexpiratory) is about $10 \mathrm{~cm}$. above fundic pressure, and the band of elevated pressure is about $2.5 \mathrm{~cm}$. in width. Pressure records from the oesophagogastric junction reveal that the band of elevated pressure at the cardia is abolished about two seconds after swallowing is initiated (Fig. 6). This relaxation of the cardia is followed by a wave of high pressure as the peristaltic wave rolls through the sphincter.

In Achalasia (CARDIospasm).-Among patients with achalasia, resting pressures in the body of the oesophagus often are equal to atmospheric pressure, presumably because of the retention of food and fluid. At the sphincters, resting pressures are similar to those in normal individuals (Creamer and others, 1957). At the oesophago-gastric junction a band of elevated pressure is recorded in achalasia, but it is no greater than in health.

With deglutition no peristaltic wave appears, but feeble, non-propulsive contractions may occur simultaneously throughout the oesophagus (Butin and others, 1953). No wave of relaxation is seen as in health (Fig. 7). Although the sphincter fails to relax, apparently it does contract in response to swallowing, for a rise in pressure at the gastrooesophageal junction has been seen regularly.
This rise begins approximately three seconds after deglutition-earlier than in health-but it is identical in duration and amplitude with the pressure increase observed at the end of the peristaltic sequence in normal persons.

The response of the oesophagus in achalasia to the injection of methacholine chloride (mecholyl) has particular significance (Hightower and others, 1954). Detectors show a distinct and prolonged increase in pressure, which usually is accompanied by severe substernal pain. The radiologists may observe a constriction of the barium-filled oesophagus. A positive finding from the mecholyl test is related to impairment of the nerve supply to the wall of the oesophagus and is pathognomonic of achalasia. There is no significant response to mecholyl in normal individuals or patients with other oesophageal disorders. Both negative and positive results in mecholyl tests are shown in Fig. 8, as well as the radiograph of the patient with achalasia.

In Diffuse Spasm.-Creamer, Donaghue, and Code (unpublished data) have investigated diffuse spasm, and their work is the basis of this description. Resting pressures in the body of the oesophagus usually are normal in diffuse spasm, and likewise the pressures at the cricopharyngeal level 


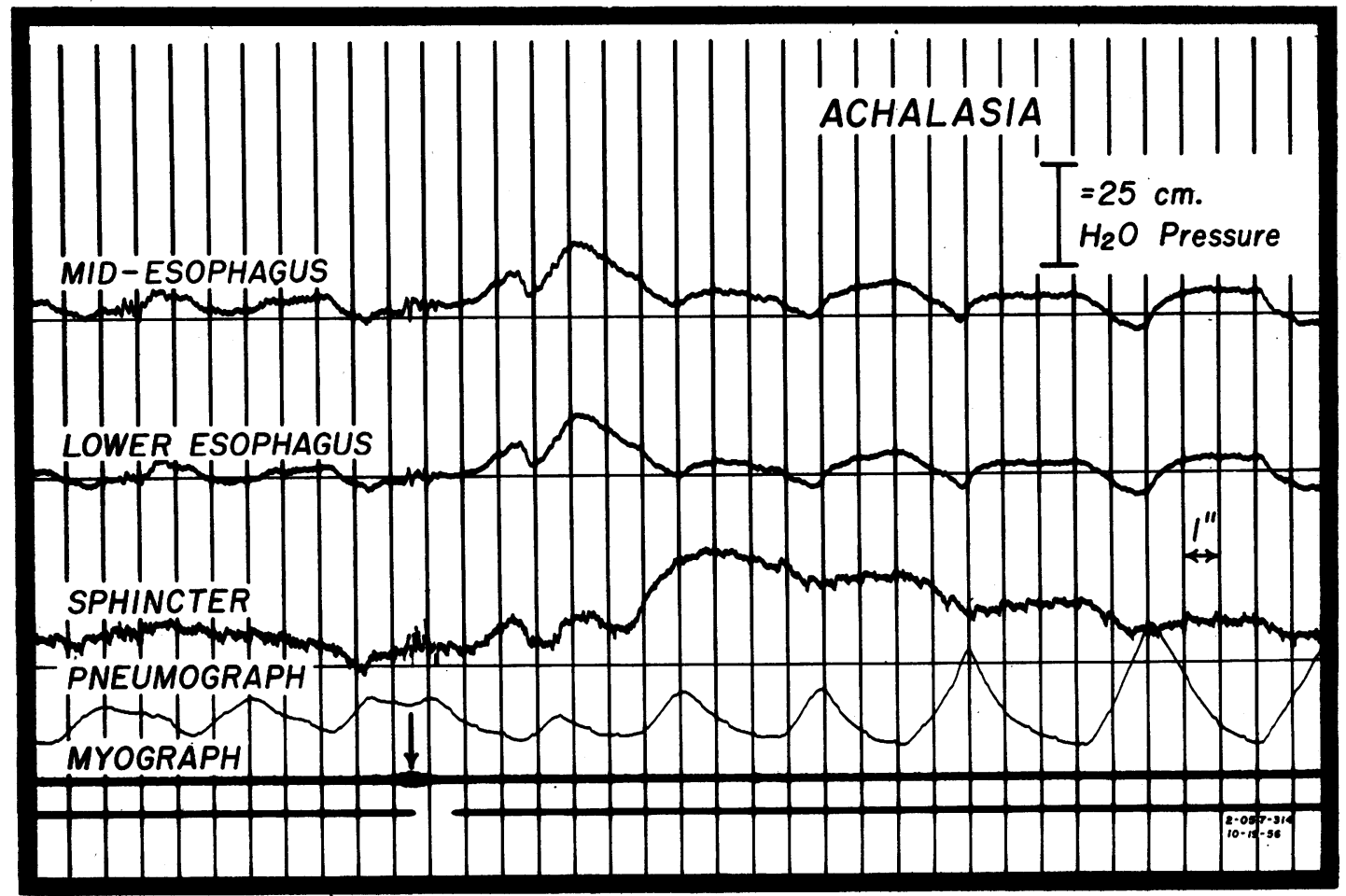

Frg. 7.-Achalasia: deglutitory pressures in oesophagus and gastro-oesophageal sphincter. Note simultaneous but feeble pressure rises and absence of wave of deglutition. (Reprinted by permission from Creamer, Brian, Olsen, A. M., and Code, C. F., Gastroenterology, 1957, 33, 293.)

are normal. At the oesophago-gastric junction, resting pressures may be similar to the normal in amplitude, but the band of increased pressure (normally $2.5 \mathrm{~cm}$.) is likely to be considerably wider, especially if hiatal hernia is associated.

Response to swallowing is normal in the upper part of the oesophagus. Deglutitory pressures in the lower half to two-thirds of the oesophagus begin earlier than the normal peristaltic wave, and are simultaneous, repetitive, and usually of much greater amplitude than the normal. Yet in response to swallowing a wave of relaxation takes place at the oesophago-gastric junction, which is similar to that in health. Pressure tracings on swallowing and a radiograph in a case of diffuse spasm are shown in Fig. 9.

\section{Clinical Differential Diagnosis}

The significant differential points between achalasia (cardiospasm) and diffuse spasm are given in Table II (Olsen, Ellis, and Creamer, 1957). In achalasia the obstruction is localized at the lower end of the oesophagus, where the inferior oesophageal sphincter fails to open because of motor failure of the oesophageal musculature. Diffuse spasm has been described by Moersch and Camp (1934) as a clinical syndrome of spastic contraction of the lower two-thirds of the oesophagus.

In cases of early achalasia the symptoms may be confusing. Pain is more likely to be present in early than in advanced achalasia, but it is usually substernal and related to the passage of food. The pain of diffuse spasm is commonly referred to the neck, shoulders, jaws, ears, or even the arms, and may or may not be related to swallowing. Diffuse spasm tends to develop in patients who are ner-

TABLE II

DIFFERENTIAL DIAGNOSIS OF ACHALASIA AND DIFFUSE SPASM*

\begin{tabular}{|c|c|c|}
\hline Symptoms and Signs & Achalasia & Diffuse Spasm \\
\hline $\begin{array}{lll}\text { Pain } & \ldots & \ldots \\
\text { Obstruction } & \ldots & \ldots \\
\text { Regurgitation } & \ldots & \ldots \\
\text { Retention } & \ldots & \ldots \\
\text { Nervousness } & \ldots & \ldots \\
\text { Radiological findings . . }\end{array}$ & $\begin{array}{l}\text { Uncommonly } \\
\text { Always } \\
\text { Commonly } \\
\text { Frequently } \\
\text { Uncommonly } \\
\text { Diffuse dilatation }\end{array}$ & $\begin{array}{l}\text { Almost always } \\
\text { Sometimes } \\
\text { Rarely } \\
\text { Never } \\
\text { Almost always } \\
\text { Segmental spasm }\end{array}$ \\
\hline
\end{tabular}

* Modified from Olsen, Ellis, and Creamer (1957). Cardiospasm (Achalasia of the Cardia). 


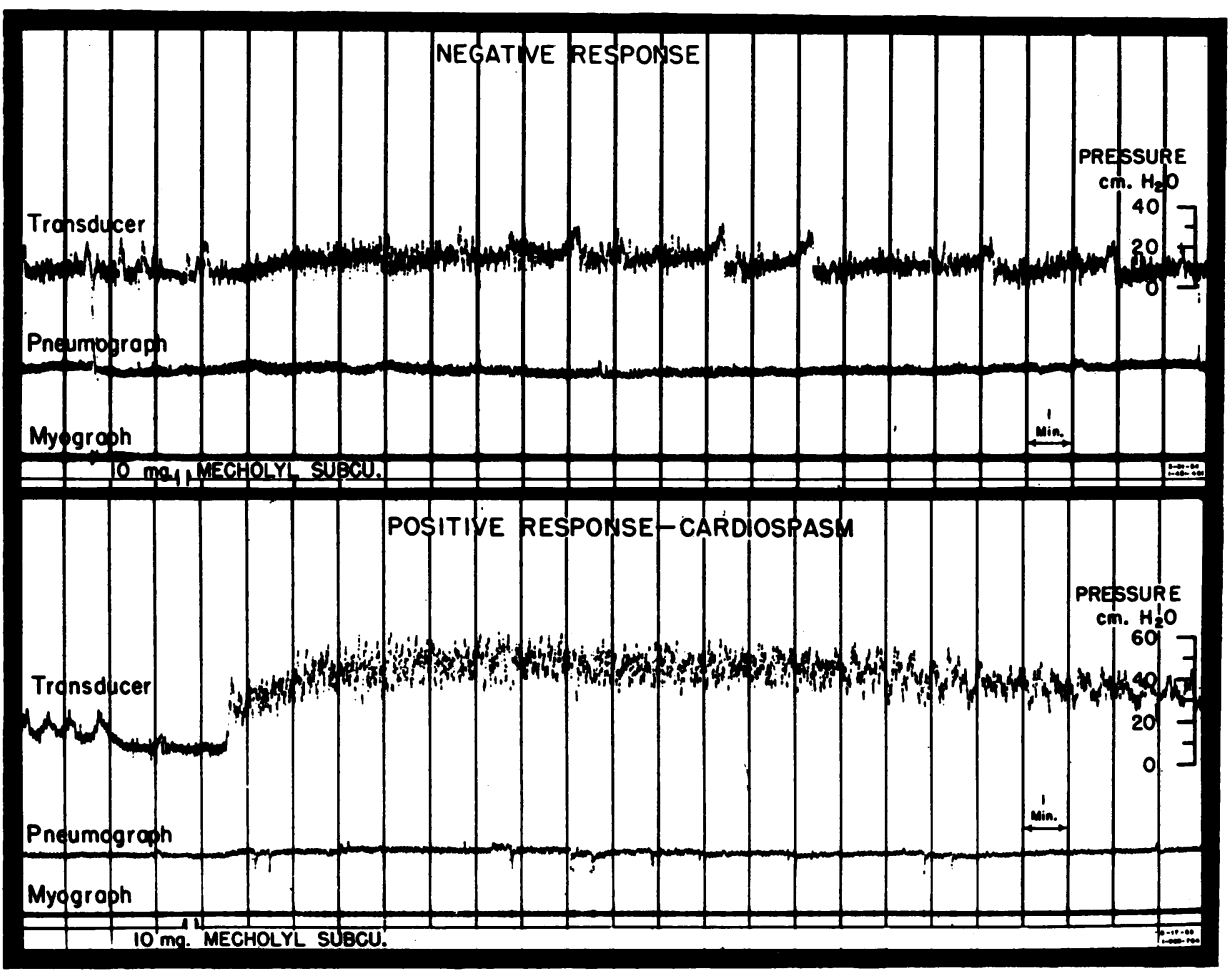

FIG. $8 a$

vous and tense, while achalasia is seen usually in persons with a stable temperament.

Radiologically, the oesophagus in achalasia is seen to be diffusely dilated with apparent constriction at the cardia (Fig. 8b). In diffuse spasm the lower half to two-thirds of the oesophagus is involved, and the radiological appearance varies from that of diffuse constant or irregular spasm to that of the multiple spastic segments designated as pseudodiverticulosis (Fig. 10). Johnstone (1956) has called attention to the hypertrophy of the oesophageal wall noted radiologically in patients with diffuse spasm, an impression verified by recent observations at the operating table (Clagett, 1957). This variety of appearance is matched by the variety of synonyms for diffuse spasm, nonsphincteric spasm, pseudodiverticulosis, segmental spasm, and curling or corkscrew oesophagus.

Actually, the last two terms probably should be reserved for the asymptomatic tertiary contractions often seen in older people. It is important to distinguish diffuse spasm from the bizarre

FIG. 8.-Pressure responses to subcutaneous injection of methacholine chloride (mecholyl). $a$, (Upper record) in health: no pressure rise. (Lower record) in achalasia: prolonged rise in pressure. $b$, Radiograph from case of positive response shown.

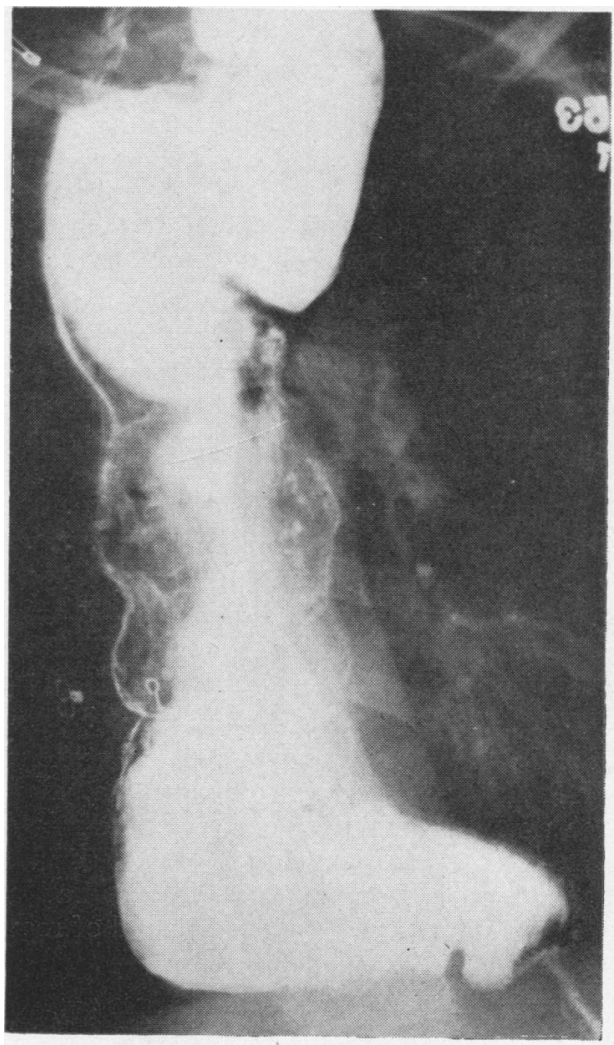




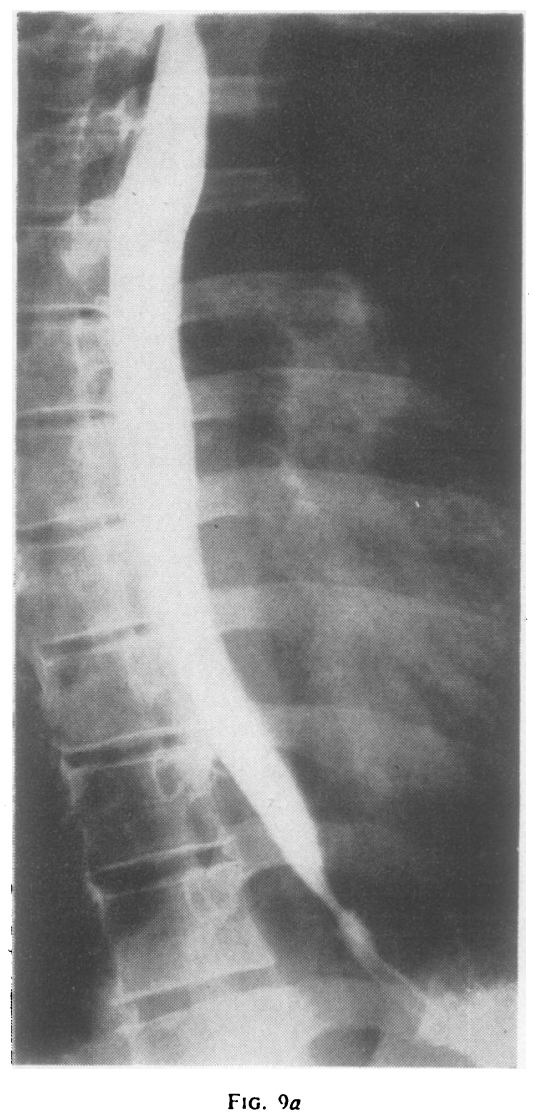

irregularity sometimes seen in treated cases of achalasia (Holman and Olsen, unpublished data).

Patients with diffuse spasm do not respond readily to any treatment. Inasmuch as diffuse spasm so frequently has been diagnosed wrongly as achalasia, not only has much confusion entered into descriptions of the clinical pattern of achalasia, but also the interpretation of the results of treatment has often been false. Patients with diffuse spasm commonly present associated gastrointestinal disorders (Schmidt, 1939); sometimes they need treatment for a deep-seated emotional problem. The results of treatment in achalasia have been excellent, the results in diffuse spasm poor.

Studies of motility have been most helpful in establishing an accurate diagnosis in perplexing cases and frequently have directed our course of treatment. A classical case is illustrated in Fig. 8. The patient, a woman 60 years old, had a long history of difficulty in swallowing and of regurgita- tion. At times she became short of breath but she never had pain. Motility studies and the mecholyl test confirmed a diagnosis of achalasia.

On the other hand, the patient whose pressure records are used for Fig. 7 did not present an easy diagnostic problem. He was a man, 39 years old, who had had progressive dysphagia for five months. He had lost $25 \mathrm{lb}$. and the oesophagus was markedly obstructed. Carcinoma of the cardia was suspected by both the clinician and the radiologist. At oesophagoscopy no oesophageal tumour could be found, but carcinoma of the stomach could not be excluded. Preliminary dilatation was performed and specimens were obtained for biopsy, which resulted negatively. Findings from the motility studies, however, were characteristic of achalasia. Hydrostatic dilatation was carried out, and the patient has been free of symptoms for two years since.

A classical case of diffuse spasm is represented in Fig. 9. The patient was a woman 26 years of age in whom dysphagia and substernal pain had developed during pregnancy two and a half years before registration. Both cold and hot foods would bring on or aggravate her pain and obstructive symptoms. Her symptoms were similarly influenced by nervous and emotional factors. The radiograph showed some diffuse narrowing of the lower part of the oesophagus but in itself was not diagnostic. Oesophagoscopy was negative. Dilatations of the oesophagus were effected without encountering any appreciable resistance either in the oesophagus or at the cardia. Motility studies showed characteristic findings of diffuse spasm. This patient has not responded to any treatment.

We have had a few patients whose clinical features suggested achalasia but whose oesophageal motility patterns were characteristic of diffuse spasm. By the same token, an occasional patient will present clinical and radiological signs of diffuse spasm and yet the motility pattern will reveal the changes of achalasia. So great is our confidence in the validity of the studies of oesophageal pressure that we consider them the final criterion of diagnosis in functional disturbances of the oesophagus.

Finally, a small group of patients have clinical and motility characteristics with some features of both cardiospasm and diffuse spasm. This may be the "mixed" group formerly thought to have both cardiospasm and diffuse spasm by clinical criteria. Their dysfunction has been thought of as "vigorous achalasia " or atypical diffuse spasm ; possibly the term "dyschalasia" may be used, as suggested by Moersch, Code, and Olsen (1957). 
NORMAL RESPONSE

DIFFUSE SPASM RESPONSE

cm. from

INCISORS:

NORMAL RESPONSE
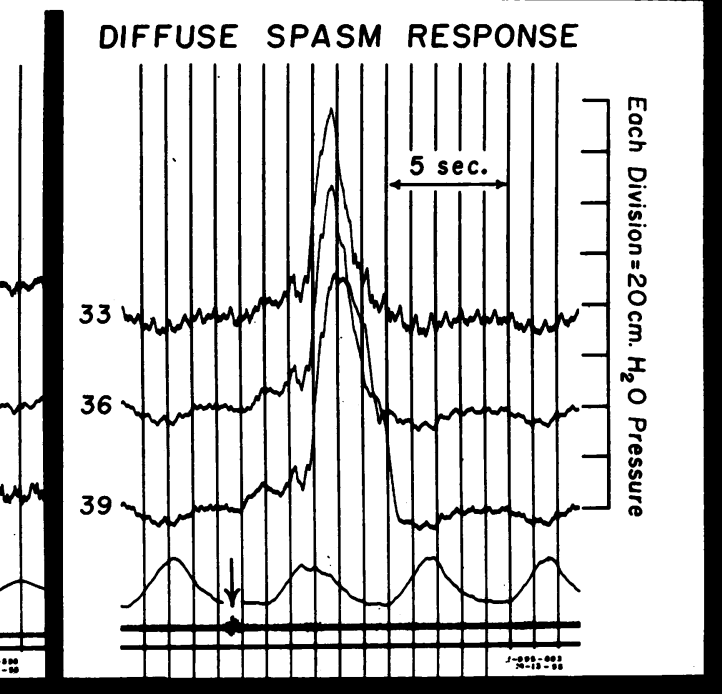

FrG. $9 b$

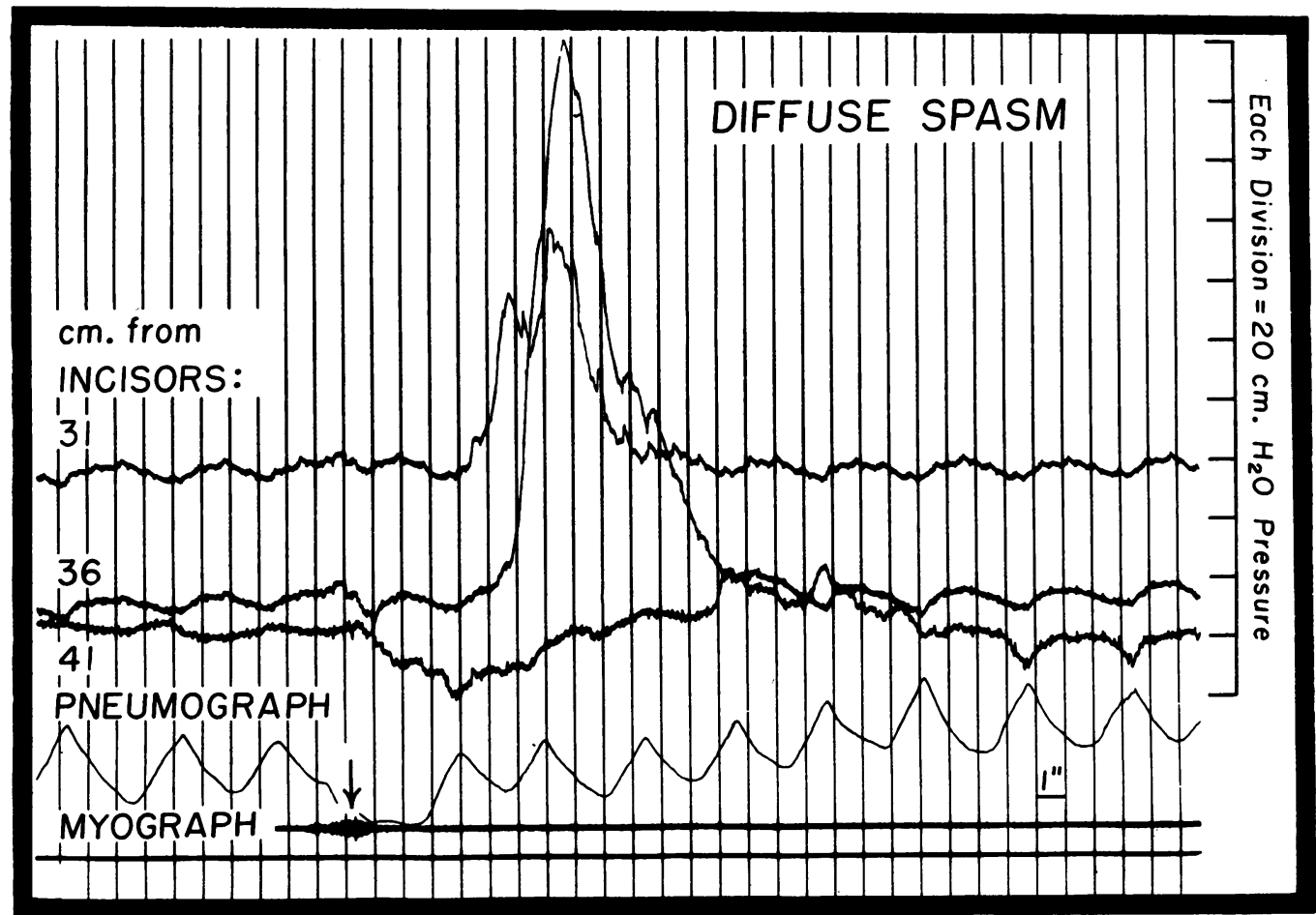

Fig. $9 c$

FIG. 9.-A classical case of diffuse spasm. $a$, Radiograph of the oesophagus. $\quad b$, Deglutitory pressures at three levels in the midoesophagus, showing simultaneous waves (right) compared with normal (left). $c$, Deglutitory pressures in lower oesophagus and lower sphincter. The wave of relaxation at the oesophago-gastric iunction is similar to the action in health. 


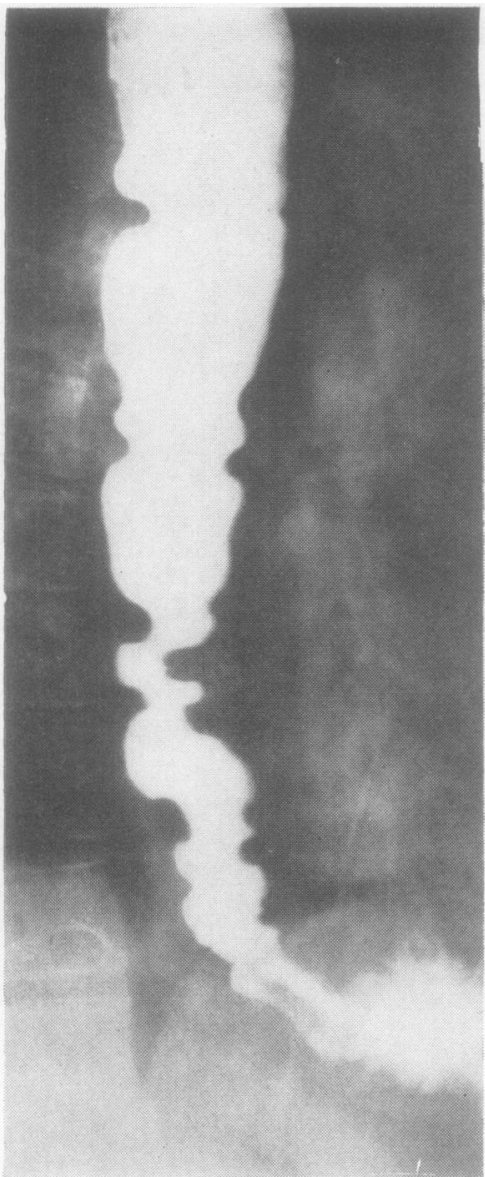

(a)

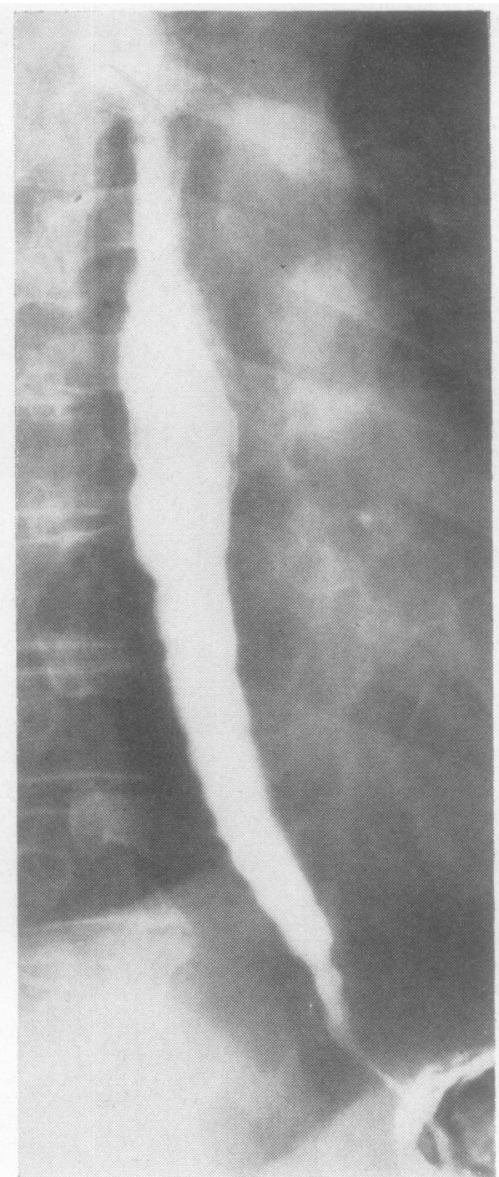

(b)

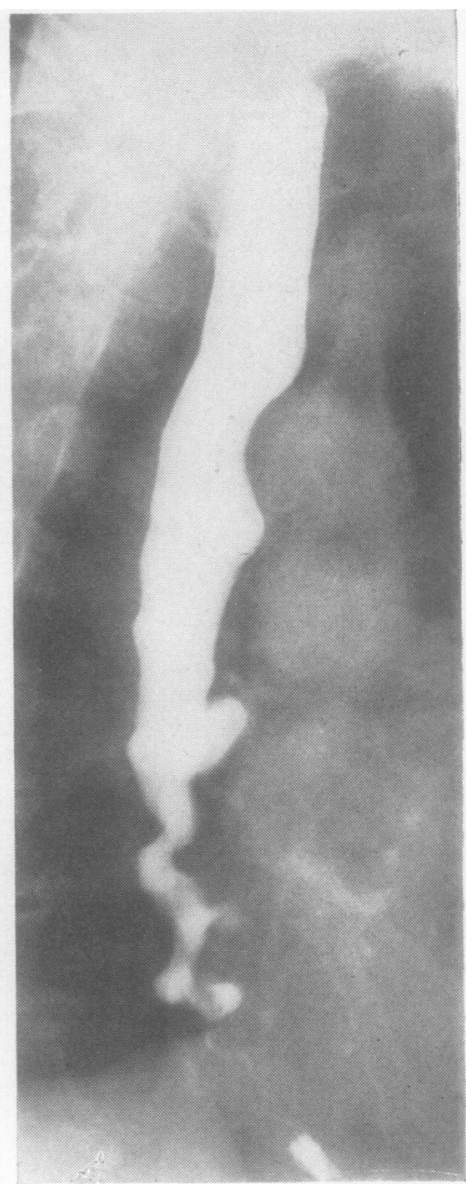

(c)

FIG. 10.-Varied appearances of diffuse spasm. $a$, Diffuse irregular spasm. $b$, Diffuse constant narrowing. $c$, Pseudodiverticulosis (Reprinted by permission from Olsen, A. M., Harrington, S. W., Moersch, H. J., and Andersen, H. A., J. thorac. Surg., 1951, 22, 164.)

\section{COMMEnT}

Diffuse spasm is certainly a dysrhythmia in the sense that ordinary peristalsis is replaced by simultaneous, vigorous contraction of the lower portion of the oesophagus. We have yet to find the trigger mechanism responsible for the disorder. Achalasia likewise is a dysrhythmia, characterized by motor failure of the oesophagus. Degeneration of Auerbach's plexus has been demonstrated repeatedly (Lendrum, 1937 : Rake, 1927) : yet the factors responsible for the histological and physiological changes have never been elicited. Etzel (1942) has attributed the condition to deficiency of thiamine chloride in the diet, but we have had no reason to suspect lack of any vitamin in our cases.

The similarities that may be present between cases of early cardiospasm and diffuse spasm might indicate that some common denominator exists. Occasionally case histories suggest that a nervous or emotional shock may precipitate a disorder of the neuromuscular mechanism controlling the oesophagus. Achalasia and diffuse spasm are usually separate entities, each with characteristic symptoms and radiological findings. In cases of doubt, studies of oesophageal pressure and the mecholyl test will almost always differentiate between the conditions. The occasional borderline cases are of special interest. Further study may give some hint as to the cause of these conditions.

\section{SUMMARY}

Cardiospasm (achalasia) and diffuse spasm of the oesophagus are separate entities. Usually these conditions can be differentiated by clinical, 
radiological, and endoscopic means. Both cardiospasm and diffuse spasm have disturbances of motility which can be readily demonstrated by the technique of measuring oesophageal pressures. The diagnosis and differential diagnosis of these disorders is made most accurately by studies of oesophageal motility.

\section{REFERENCES}

Butin, J. W., Olsen, A. M.. Moersch, H. J., and Code, C. F. (1953) Gastroenterology, 23, 278.

Cannon, W. B. (1911). The Mechanical Factors of Digestion. Arnold, London.

Carlson, A. J., and Luckhardt, A. B. (1921). Amer. J. Physiol., 57, 299.

Clagett, O. T. (1957). Personal communication to the authors.

Creamer, Brian, Olsen, A. M., and Code, C. F. (1957). Gastroenterology, 33, 293.

Dornhorst, A. C., Harrison, K., and Pierce, J. W. (1954). Lancet, 1, 695 .
Etzel, E. (1942). Amer. J. med. Sci., 203, 87.

Fyke, F. E., Jr., and Code, C. F. (1955). Gastroenterology, $29,24$.

$-\frac{135 .}{135}$ and Schlegel, J. F. (1956). Gastroenterologia (Basel), 86,

Gauer, O. H., and Gienapp, E. (1950). Science, 112, 404.

Hightower, N. C., Jr., Olsen, A. M., and Moersch, H. J. (1954). Gastroenterology, $26,592$.

Johnstone, A. S. (1956). Gastroenterologia (Basel), 86, 164.

Kramer, P., and Ingelfinger, F. J. (1949). Amer. J. Med., 7, 168.

Kronecker, H., and Meltzer, S. (1833). Archiv. für Anatomie und Physiologie (Physiol. abt.), Suppl., p. 328.

Lendrum, F. C. (1937). Arch. intern. Med., 59, 474.

Moersch, H. J., and Camp, J. D. (1934). Ann. Otol. (St. Louis), 43, 1165.

_Code, C. F., and Olsen, A. M. (1957). Read at the Sixth International Congress of Bronchoesophagology, Philadelphia, Pennsylvania, May 11 to 13, 1957.

Olsen, A. M., Ellis, F. H., Jr., and Creamer, B. (1957). Amer. J. Surg., 93, 299.

Rake, G. W. (1927). Guy's Hosp. Rep., 77, 141.

Schmidt, H. W. (1939). Amer. J. dig. Dis., 6, 693.

Wetterer, E. (1943). Z. Biol., 101, 332. 